Volume 15, Número 3, set./dez. de 2021

\title{
Ana Regina Rêgo: uma rede para combater a desinformação
}

\section{Ana Regina Rêgo: a network to fight disinformation}

\section{Ana Regina Rêgo: una red para combatir la desinformación}

\author{
Rogério CHRISTOFOLETTI ${ }^{1}$
}

\begin{abstract}
Resumo
A professora Ana Regina Rêgo, da Universidade Federal do Piauí, coordena a Rede Nacional de Combate à Desinformação (RNCD), coletivo de iniciativas acadêmicas, profissionais e ativistas que produzem e apresentam soluções para enfrentar boatos, narrativas enviesadas e falsidades. Nesta entrevista, feita em junho de 2021 por e-mail, a pesquisadora descreve o funcionamento desse coletivo que já tem mais de 120 parceiros espalhados pelo país, e aponta alguns dos principais desafios no combate às mentiras e à manipulação informativa, como as estratégias do capitalismo de vigilância, adotadas pelas grandes plataformas digitais.
\end{abstract}

Palavras-chave: Desinformação. Big techs. Capitalismo de vigilância.

\begin{abstract}
Ana Regina Rêgo is a professor at the Federal University of Piauí and heads the National Network to Combat Disinformation (RNCD), a hub of academic, professional and activist initiatives that face rumors, biased narratives and falsehoods. In this interview, carried out in June 2021 by email, the researcher describes the functioning of the network, which already has more than 120 partners throughout Brazil, and points out some of the main challenges in combating lies and informational manipulation, such as the strategies of capitalism in surveillance, adopted by the big techs.
\end{abstract}

Keywords: Disinformation. Big techs. Surveillance capitalism.

\section{Resumen}

Ana Regina Rêgo es profesora de la Universidad Federal de Piauí y lidera la Red Nacional de Combate a la Desinformación (RNCD), un colectivo de iniciativas académicas, profesionales y activistas que producen y presentan soluciones para enfrentar rumores, narrativas sesgadas y falsedades. En esta entrevista, realizada en junio de 2021 por correo electrónico, la investigadora describe el funcionamiento de este colectivo, que ya cuenta con más de 120 socios en Brasil, y señala algunos de los principales desafíos en el

\footnotetext{
1 Professor do Departamento de Jornalismo da Universidade Federal de Santa Catarina (UFSC). Pesquisador do CNPq (PQ-2). E-mail: rogerio.christofoletti@ufsc.br. ORCID 0000-0003-1065-4764.
} 
combate de la mentira y la manipulación informativa, como las estrategias del capitalismo de vigilancia, adoptado por las grandes plataformas digitales.

Palabras clave: Desinformación. Plataformas digitales. Capitalismo de vigilancia

\section{Apresentação}

A difusão massiva de conteúdos que distorcem, falseiam e desorientam tornou-se uma das principais preocupações sociais da atualidade. Se boatos simples já causavam transtornos coletivos, campanhas bem-estruturadas e amplamente distribuídas podem contribuir com o espalhamento do caos, o aumento dos discursos inflamatórios e o esgarçamento do tecido social. O alerta sobre o perigo da desinformação já soou nas empresas, nos governos e entre cidadãos mais comprometidos e atentos à deterioração da democracia e de valores como a verdade factual, o conhecimento científico e a informação jornalística de interesse público.

Não se trata de uma ameaça restrita a um país nem circunscrita a um modo de vida. Sob os rótulos da "pós-verdade" ou da "desordem informativa", o fenômeno tem volume, dinâmica e capilaridade inéditos, contaminando todas as geografias, infiltrandose e corrompendo comportamentos e culturas. Pior ainda: replicou o DNA do capitalismo, apropriando-se de suas características mais nefastas, convertendo-se numa forma de exploração e de extração de rentabilidade de grande parte da população mundial. $\mathrm{O}$ capitalismo de vigilância está por trás do sucesso dos maiores conglomerados digitais do planeta, e ele se aproveita dos dados pessoais dos sujeitos, gerando perfis sociais, políticos e de consumo, todos monitoráveis e todos controláveis por meio de sofisticadas estratégias de manipulação informativa e indução comportamental.

Se a vida contemporânea quase não pode mais ser sustentada off-line, como escapar de armadilhas que sequestram nossos dados, monetizam nossas vidas, e desviam nossos olhares para miragens e mentiras? Como enfrentar um cenário coalhado por um sólido e opaco ecossistema de desinformação? Que soluções podem ser pensadas a partir dessa realidade?

Os questionamentos são angustiantes e inadiáveis e, por isso, recorremos a uma resposta concreta e atual: a Rede Nacional de Combate à Desinformação. Criada em 2020 
por um punhado de pesquisadores, hoje reúne mais de 120 iniciativas de dentro e fora da academia, que fazem um corajoso enfrentamento das narrativas mentirosas e dos discursos inflamatórios. A professora Ana Regina Rêgo coordena a RNCD e, na entrevista a seguir, conta como funciona a rede e que resultados vem-se colhendo com o trabalho de revelar, desmentir e contrapor.

R.CHRISTOFOLETTI: Como surgiu a ideia de uma rede de combate à desinformação nesses moldes?

A.R.RÊGO: Em primeiro lugar, gostaria de agradecer o convite para a entrevista. É sempre muito bom ter espaço para uma boa interlocução, assim como, para divulgar, não somente o trabalho da $\mathrm{RNCD}$, mas o que a rede representa e sua conformação em parcerias.

A Rede Nacional de Combate à Desinformação (RNCD) nasceu inicialmente de um primeiro desenho que surgiu ao longo da pesquisa que fiz para o PósDoutorado na UFRJ em 2019. Os resultados da pesquisa que deram origem ao livro A construção intencional da ignorância apontavam para o fato de que era e ainda é necessária uma reação em cadeia ao fenômeno social da desinformação em nosso país. Algo que tem provocado transformações políticas complexas e que se aproxima do Ur-fascism no sentido de Umberto Eco (2018), e, que em outra frente, neste momento de pandemia, tem levado pessoas a evitar medidas que poderiam salvar vidas.

Posteriormente, terminei inserindo a ideia da rede no que seria um passo inicial para um projeto de pesquisa maior desenvolvido para o $\mathrm{CNPq}$ e que, apesar de aprovado, ficou entre os que não foram contemplados com recursos. No início de 2020, tentei criar uma rede de monitoramento e checagem de fatos no Projeto Mandacaru, onde atuei por alguns meses na condição de voluntária e que era um projeto vinculado ao Comitê Nordeste de Combate à Covid, que por sua vez, era uma iniciativa do Consórcio de Governadores do Nordeste. Não obtive êxito por lá e resolvi retornar ao campo da Comunicação onde amigos e muitos conhecidos 
abraçaram a ideia, que consiste na simples intenção de um “dar as mãos”, unir os trabalhos que já desenvolvemos em nossos lugares, dando a conhecer em uma dimensão muito maior, formando uma corrente de enfrentamento ao ecossistema da desinformação.

R.CHRISTOFOLETTI: Como a rede pode contribuir para o enfrentamento da desinformação no Brasil?

A.R.RÊGO: Antes de falar das contribuições da RNCD Brasil, vou entrar rapidamente em uma discussão conceitual de que se ocupa a academia no momento e que eu, particularmente, procuro respeitar todos os pontos, contudo, tendo como horizonte a visualidade da desinformação não como conceito e sim como fenômeno social que em si, se interliga ao fenômeno da informação, se localizando como seu outro lado, o que consegue sucesso exatamente quando se passa por seu lado de "luz", a informação, que em si, deveria se consumar como conhecimento comunicado e não como veículo de propagação de narrativas que constroem (RÊGO; BARSOSA, 2020) ou mantêm (BURKE, 2021) um tipo específico de ignorância social coletiva. É certo que alguns pensadores como Igor Sacramento (2021) e Wilson Gomes (2021) esclarecem sobre a importância de não se perder de vista a nomenclatura fake news, mas mesmo assim, me sinto muito mais inclinada a manter as fake news como parte do fenômeno, mantendo ainda uma concordância com Peter Burke (2018) que já alertava para a potencialização da mentira. No Reino Unido, Wardle e Derakhshan (2017) cunharam uma tríade de conceitos para dar conta do que denominaram de "desordem informacional" e que, a meu ver, ainda não são suficientes. Eles tratam de "disinformation", "misinformation" e "mal-information", visto que o fenômeno possui lugares e morfologia mutantes. No que concerne ao locus de produção, há um mercado pujante e lucrativo; há ainda uma grande parcela da população que, dominando os meios de produção de conteúdos, também se dedica a produzir desinformação e há, sobretudo, uma grande parcela da população brasileira que consome desinformação sem praticar 
nenhum movimento mínimo de criticidade ou de levantamento da dúvida. Quanto à morfologia, temos observado a complexidade na composição das narrativas cada vez mais híbridas. Não se trata mais, como em 2018, de somente criar uma narrativa sobre uma ficcional mamadeira de piroca, ou, um kit gay, mas de mesclar fatos com fraude, com fatos descontextualizados que podem se misturar ainda com narrativas ficcionais que podem vir, por exemplo, a compor uma teoria mundial da conspiração, nos moldes do QAnon.

Então, diante do cenário mencionado acima, em que o fenômeno da desinformação se apresenta complexo, veloz e com potencial crescente em nosso país, retorno à pergunta de como a RNCD pode contribuir para minimizar os efeitos da desinformação e começo afirmando que se trata de uma iniciativa que até o presente momento, não possui nenhum investimento financeiro, sendo, portanto, uma organização virtual informal que se caracteriza pelo voluntariado em diversos níveis e que possui muitos parceiros em situação similar e que, em comum, possuem a vontade de compreender e combater o ecossistema da desinformação.

Dito isso, vale pensar a RNCD como uma organização virtual coletiva que, para mim, enquanto pesquisadora do campo da comunicação e do jornalismo há mais de duas décadas, se configurou como uma total quebra de paradigma, visto que os caminhos da rede nos levaram para diversas áreas das ciências e do conhecimento, para além de diversos lugares de atuação, em que se trabalha de algum modo tentando desconstruir a desinformação circundante ou contribuindo para a disseminação do conhecimento.

Nesse sentido, a contribuição da rede parte da possibilidade de - ao unir projetos, instituições, coletivos, laboratórios, observatórios, museus, ONGs, movimentos populares, aplicativos etc. - aproveitar a forma com a qual cada um dos atuais 120 parceiros já trabalham para seus públicos em seus lugares e potencializar a visibilidade das temáticas com as quais os parceiros trabalham, fazendo chegar por diversos meios, tipos e modalidades de narrativas, o conhecimento necessário a uma parcela muito maior da população brasileira. 
Para clarificar, destaco que temos vários parceiros das ciências (imunologia, farmácia, biologia...) que trabalham com divulgação científica e uma temática em que estamos atuando muito fortemente é a da conscientização sobre a importância da vacinação. Esta é uma temática trabalhada de forma contrária pelo mercado da desinformação e pelo que denominamos de movimento antivacina que retornou com grande força durante a pandemia e que tem plantado muitas dúvidas na população brasileira.

Um exemplo: recebemos uma denúncia ou dúvida de um cidadão através do aplicativo Eufiscalizo Fiocruz sobre os efeitos de alguma vacina, ou se a vacina vai matar a todos em até dois anos, ou se a vacina implanta um chip 5G. Repassamos a questão para um parceiro da checagem jornalística que retorna com uma matéria, comumente grande e que não é exatamente a melhor narrativa para fazer circular nas redes sociais e aplicativos de mensagem. Essa matéria é publicada nos sites do aplicativo e no parceiro de checagem e devolvida aos usuários do aplicativo. Todavia, neste caso, os parceiros de divulgação científica trabalham cards, vídeos, conteúdos para TikTok, e fazem circular uma mensagem esclarecedora por diversos meios, fazendo chegar até os grupos de família e de religiões que são considerados grande fruidores de fake news no Brasil. Então, a ideia é que cada parceiro em seu lugar atenda a seu público com uma mensagem que circula entre muitos parceiros, conforme suas próprias programações e formas de produção, e isso provoca reações em cadeia que envolvem projetos e iniciativas que não são parceiros da rede, mas que se aproximam pelas mídias sociais e que passam a compartilhar conteúdos e marcar parceiros e a própria RNCD quando as temáticas são de interesses múltiplos.

Portanto, no que concerne a uma efetiva contribuição da rede neste momento, avaliamos que ainda esteja em um estágio inicial e pequeno, principalmente quando comparamos com o mercado da desinformação, mas com grande potencial de crescimento ao longo dos próximos meses e anos. 
R.CHRISTOFOLETTI: Professora, uma rede costuma operar de forma aleatória, espalhada e descontínua. Essas características podem ser positivas para aumentar a visibilidade de iniciativas menores e para ampliar a capilaridade dessas ações. Mas isso também pode resultar num trabalho mais próximo de uma colcha de retalhos. Como fortalecer a rede no sentido de uma ação mais organizada?

A.R.RÊGO: Essa pergunta é muito importante e interessante porque traz um grande paradoxo que aproxima e opõe reticularidade e liberdade, por um lado, com coordenação e organização estratégica, por outro.

Quando criamos a RNCD, não tínhamos nenhuma intencionalidade de intervir na ação dos parceiros e, portanto, a coordenação seria mínima e simbólica. Obviamente, isso talvez vá contra a minha própria experiência de longa data como gestora organizacional em uma grande estatal brasileira, e, embora eu venha eventualmente sendo pressionada por alguns parceiros para que a RNCD coordene ações holísticas que envolvam todos os parceiros ou a maioria deles, deflagrando ações coordenadas, nosso caminho não nos leva até o presente momento a esse tipo de atuação mais organizacional.

Como já disse, a rede tem sido uma total quebra de paradigma não somente no que concerne à percepção de que o fenômeno da desinformação é de interesse de todas as áreas do conhecimento, mas também, pelo modo como cada parceiro atua e como cria redes paralelas potencializando as articulações que se iniciam em seus lugares e que posteriormente chegam até a RNCD e ganham a sociedade.

Efetivamente, não temos a intenção de criar uma estrutura vertical ou mesmo horizontal de gestão que venha a interferir na ação dos parceiros. O que estamos criando é uma mínima estrutura que nos ajude a conhecer melhor os parceiros da rede e, desse modo, potencializar as interações entre parceiros que possuem metas e temas comuns.

Hoje, a RNCD tem a coordenação geral - que ainda está comigo, mas que temos a intenção de fazer rodízio futuramente -, tem as coordenações de pesquisa - que 
foi assumida pelo Edgar Rebouças que possui dois projetos na rede -, a de formação - que está com Pollyana Ferrari - e a coordenação de eventos - que a Rachel Bertol assumiu recentemente. A ideia é realizar programações que não venham a interferir nas ações dos parceiros, mas que possam somar e dar visibilidade aos trabalhos, visto que a RNCD, em menos de um ano, se tornou maior do que a maioria das instituições do campo da Comunicação e precisa de uma orientação mínima.

Pensando nesses moldes, na pesquisa, pretendemos o quanto antes abrir uma página na plataforma para publicar estudos já publicados de parceiros e nãoparceiros sobre a temática, como também, projetos de pesquisa no campo da desinformação que estejam em andamento.

No campo da formação, a ideia é fazer com que parceiros contribuam com a formação dos demais pares e até do público externo que tenha interesse. Concluímos recentemente a oficina "Monitoramento do debate público nas redes sociais" apresentada pela Diretoria de Análises de Políticas Públicas - DAPPFGV, que é nossa parceira com o projeto Democracia Digital. A oficina foi oferecida apenas internamente e teve a adesão de 40 parceiros. Agora no segundo semestre, estão previstas oficinas com Instituto Devir Educom, Vaza Falsiane e Instituto Palavra Aberta, mas qualquer parceiro pode propor algo do tipo.

A coordenação de eventos está programando atividades mensais até o final do ano com temáticas que envolvem parceiros em suas áreas, procurando juntar os que possuem atuação similar. No primeiro semestre, tivemos um evento com a DAPPFGV, outro com três parceiros de divulgação científica e outro com o historiador Peter Burke sobre a complexa temática da ignorância na política.

Mesmo com essa mínima organização, ainda somos adeptos da total liberdade dos parceiros para compor novas redes e formar mais parcerias internas e externas, visto que nossa intenção é chegar a um público cada vez maior. Cito dois exemplos. $\mathrm{O}$ primeiro é a campanha \#todospelasvacinas (https://www.todospelasvacinas.info/), lançada em janeiro e que teve adesão de muitos artistas famosos, chegando a uma grande visibilidade e adesão. Nossos 
parceiros - UP Vacinas, Observatório Covid-BR e Rede de Análise da Covid-19 - se juntaram a outras instituições e projetos que não estão na rede e realizaram uma iniciativa de grandes proporções que continua no ar, com muito material disponível para qualquer pessoa baixar e usar em suas redes pessoais. Neste caso, a RNCD trouxe a campanha para também se tornar uma parceira e deu total apoio na divulgação. A outra iniciativa veio da parceira ANDA News: o \#parepelomeioambiente (https://parepelomeioambiente.org/). Consistiu em um documento, assinado por personalidades e instituições, que foi enviado para o Parlamento Europeu, o presidente dos Estados Unidos e o Mercosul, denunciando os desmandos do governo brasileiro no meio ambiente, e, por outro lado, se materializou em um evento realizado em 5 de junho com a adesão de muitos artistas. Então, a contribuição da RNCD está intimamente ligada à potência de contribuição de seus parceiros. A RNCD é sinônimo de parcerias.

R.CHRISTOFOLETTI: $U m$ dos grandes problemas de iniciativas de pesquisa $e$ extensão é a sua sustentabilidade financeira. Algumas big techs têm destinado recursos para combater a desinformação, mas essas corporações também são acusadas de promover conteúdos enganosos e discursos de ódio. Há uma questão ética embutida nisso. Como a RNCD vê isso? Há alguma orientação para os membros da rede?

A.R.R̂EGO: Novamente, chegamos a um grande paradoxo - sustentabilidade necessária e ponderação em relação a parcerias com as plataformas digitais, sobretudo, pelas questões éticas - que envolve e opõe apoio financeiro ao modelo de negócios predatórios das plataformas.

O modelo de negócios das big techs, como nos mostra claramente Shoshana Zuboff (2020), conforma e atualiza constantemente o atual estágio do capitalismo de vigilância, que coloca o usuário no core business das plataformas, explorandonos de todas as perspectivas possíveis, e que tem como valor principal o que denominam de capital de predição comportamental que se forma a partir da 
vigilância holística dos usuários em seus perfis digitais. Na outra ponta, esse processo revela ainda o complexo modelo de estratégias de investimento em visibilidade de conteúdos com potencial lucrativo e silenciamento de conteúdos de perfis que se recusam a aderir às imposições das redes sociais.

A desinformação, fenômeno de grande potencial de circulação e de formação da opinião, aproveita a arquitetura de segregação de narrativas, utilizadas pelas plataformas e termina por agregar pessoas com pensamentos, valores e crenças similares em câmaras de eco, invisibilizando as narrativas que circulam para além das câmaras, limitando o acesso à informação contrária e isolando os indivíduos em suas visões restritas de mundo.

É exatamente essa potência para a adesão da opinião pública que se consolida através da grande fruição e visibilidade que é explorada pelas plataformas visto que estas vendem, além do nosso comportamento futuro, a nossa atenção, em um processo de economia da atenção que nos mantém reféns da biosvirtual, mantendo-nos presos à atualização de conteúdo constante (RÊGO, 2021), seja ele qual for, o que torna a desinformação muito atrativa e lucrativa.

Segundo o Instituto de Tecnologia de Massachusetts (MIT), as narrativas falsas ou fraudulentas possuem potencial de circulação $70 \%$ maior do que as informações jornalísticas e ou científicas (NOTÍCIAS..., 2018). Por isso, a desinformação é tanto lucrativa para os perfis, sites e canais que a produzem quanto para as plataformas digitais e para os anunciantes que fazem contratos diretamente com as plataformas, não sabendo, muitas vezes, onde sua logomarca vai parar, visto que o contrato é cego pelos dois lados e o valor investido é direcionado ao perfil de maior audiência. Temos então um círculo pernicioso à informação, ao conhecimento e ao jornalismo, que não conseguem competir com as dimensões do mercado da desinformação.

Vale ponderar que os perfis do Sleeping Giants no Brasil e nos Estados Unidos têm trabalhado incessantemente para desvelar tais negociações, informando às empresas que canais e perfis de desinformação estão patrocinando, atuando para a sua desmonetização. 
Desse modo, a RNCD vê com muita cautela tais associações, como as que estão em vigor entre plataformas digitais, sobretudo com o Facebook, considerado pela pesquisadora Carissa Véliz (2020) um abutre de dados. Visualizamos, no entanto, caminhos para o diálogo em parcerias com agências de checagem que podem reduzir os efeitos e os danos que a desinformação vem causando à democracia e à saúde do povo brasileiro, desde que haja margem de negociação e de liberdade entre os patrocinados e as plataformas patrocinadoras, o que não é lá muito fácil ou mesmo comum.

Não há uma orientação da RNCD para seus parceiros sobre isso, pois prezamos pela liberdade de atuação, desde que dentro de princípios não-fascistas, nãohomofóbicos, não-racistas, não-misóginos etc.

Por fim, creio que teremos que pensar em como conviver não somente com as plataformas, mas dentro das plataformas, como já vivemos, de modo crítico, atuante e partícipes das decisões que incluam a vida em sociedade.

R.CHRISTOFOLETTI: Quem se aventura a combater a desinformação acaba enfrentando também resistência de grupos violentos que difundem também discursos de ódio e de segregação. A RNCD já provou desse sabor amargo, e teve seu site derrubado por ataques cibernéticos. Como contornar essas agressões e continuar esse trabalho?

A.R.RÊEG: Considero bem difícil e complexo o processo híbrido em que desinformação e discurso de ódio se intercambiam em uma simbiose muito perigosa para as sociedades na atualidade. Com motivações múltiplas, os agentes da desinformação são também agentes do ódio e podem levar algumas pessoas a ações extremas como vimos na Inglaterra durante a campanha do Brexit em 2016, quando a deputada Jo Cox, que defendia a permanência na União Europeia, foi assassinada por um simpatizante da extrema direita britânica, incitado pelas narrativas que destilavam ódio na campanha dos que defendiam a saída da UE. 
Esse é somente um exemplo do que tem ocorrido em vários países, inclusive no Brasil, onde as campanhas de ódio têm levado parlamentares, personalidades, pesquisadores e cientistas a deixar o país, quando perseguidos pelo que se denomina por aqui, genericamente, de "milícias digitais", que ameaçam, perseguem e chegam a cometer violências físicas em diversos momentos.

No final de janeiro deste ano, a plataforma da RNCD, com somente quatro meses de atuação, sofreu um ataque de hackers e ficou um mês fora do ar, até que conseguíssemos resolver todos os problemas de segurança. Contudo, vivemos sobressaltados, pois somos, como dito, uma organização virtual informal e não temos patrocinadores, não temos recursos para investir em uma arquitetura de segurança máxima. Os custos, nesse ambiente, como em outros, em geral, sou eu mesma que pago e conto com a ajuda da empresa que nos assessora e que cobra valores bem menores do que o mercado, pois acredita e apoia a iniciativa.

Acreditamos que, no momento atual, não podemos recuar. Obviamente, todos os cuidados devem ser tomados, mas temos limites de investimentos. Então, também devemos articular no âmbito político junto ao Congresso na construção do PL 2630/2020, que parece que está retornando à pauta, além de apoiar e fazer denúncias junto à CPMI das Fakes News (que está parada no momento) e à CPI da Covid-19 que está a pleno vapor... Todas essas iniciativas do Congresso Nacional são de máxima importância, tanto para a visualidade do problema que envolve o fenômeno da desinformação e do ódio, como para apontar soluções legislativas que possam proteger a sociedade brasileira.

R.CHRISTOFOLETTI: A vida em rede tem facilitado a criação de câmaras de eco e o embotamento das pessoas em grupos que reverberam suas idiossincrasias. Combater a desinformação, muitas vezes, é enfrentar resistências cognitivas. $O$ que podemos fazer para não nos limitarmos a pregar para os convertidos?

A.R.R̂EGO: Existem controvérsias no que concerne às câmaras de eco e bolhas digitais. Se por um lado, há inúmeros estudos e até depoimentos dos cientistas que 
formataram as estratégias mais recentes das plataformas digitais que apontam para o direcionamento crescente dos algoritmos e para a construção de experiências tranquilas para os usuários com feed de notícias onde só encontramos concordantes; por outro, há estudos como o de Seth Flaxman, pesquisador da Universidade de Oxford, e Elizabeth Dubois, da Universidade de Ottawa, que apontam para o fato de que existem bolhas e câmaras de eco, mas que a dieta de mídia é bem mais variada do que se pensa (POR QUE..., 2018).

Contudo, vale pensar que, mesmo que uma grande parte da população com criticidade e educação midiática pulverize seus modos e lugares de consumo de conteúdo, uma parcela ainda bem considerável se mantém refém de conteúdo produzido para redes sociais e aplicativos de mensagens, reforçando os espaços que fazem reverberar ideologias complicadas e que podem acionar o ódio coletivo.

Nesse contexto, a atuação das plataformas e suas arquiteturas de orientação ao usuário têm sido fundamental, como no caso do Facebook que, para Franklin Foer (2018), trabalha de modo paternalista para direcionar seus usuários para perfis, lugares e opiniões que considera, a partir da programação de seus algoritmos, “melhor" para o público, mas que, em verdade, são escolhas da própria plataforma com vistas a potencializar o crescente superávit comportamental, como nos diz Shoshana Zuboff (2020), prática iniciada pelo Google, mas seguida pelas demais big techs. Ou seja, o agrupamento dos perfis digitais dos usuários por opinião e valores termina formando bolhas, já que os algoritmos não permitem que vejamos em nosso feed de notícias o restante da esfera virtual. Contudo, a formação das câmaras de eco ideológicas tem sido denunciada por muitos analistas, uma vez que elas potencializam o desentendimento político, adotado aqui na visão de Jacques Rancière (2018), dificultando o diálogo entre pensamentos divergentes, considerando que só conversamos com pares.

Vale destacar que o desentendimento na visada de Rancière não é provocado pelo desconhecimento puro, nem pela imprecisão das palavras, mas ocorre quando um 
ou mais interlocutores manifestam um efeito de simples ignorância ou dissimulação, acarretando com que um não reconheça o que o outro diz. É bem verdade que já existe uma pressão pela quebra dos movimentos estratégicos dos algoritmos, objetivando abrir as vias que limitam o debate digital permitindo uma amplificação do debate para além das bolhas.

Por outro lado, há que se pensar que as argumentações construídas dentro de um ecossistema da desinformação, reverberadas nas câmaras de eco, possuem uma formatação que envolve inacessibilidade a padrões cognitivos pessoais, dificultando o agir comunicativo como caminho para o diálogo imparcial, a inclusão e visualidade completa da oposição, liberdade de opinião e facilidade de interação com o outro, conforme explica Habermas (2019) ao definir tal modo de agir. É nesse caminho que, em uma investigação anterior publicada em parceria com Marialva Barbosa (2020), apontamos para as dificuldades e resistências cognitivas que terminam por reforçar o desejo de permanecer na ignorância.

Não falar somente para os pares é um desafio que pressupõe uma ação direcionada para o ouvir, ouvir o outro, para a partir de então compreender o seu processo de interpretação do mundo. Reconheço o imenso desafio que isso representa para nós no momento atual. É muito mais fácil praticar o julgar do que o ouvir. Julgamos, vociferamos e afastamos amigos e familiares com os quais poderíamos tentar dialogar. $\mathrm{O}$ ouvir pressupõe não ser tomado pela raiva na hora em que recebemos um comentário violento em nosso perfil pessoal sobre algum posicionamento político externado. Significa deixar o outro falar de suas angústias e inquietações, para posteriormente verificar o que foi pautado em experiências negativas, em narrativas desinformantes e/ou em discursos de ódios, com o intuito de abrir caminho para o diálogo. Às vezes, o mais importante é atuar de forma estratégica, repassando conteúdos que podem contribuir positivamente para o debate sem partir para o confronto direto. 
R.CHRISTOFOLETTI: No âmbito legal, a seu ver, que tipos de regulações deveriam ser adotados para combater a desinformação sem comprometer a liberdade de expressão?

A.R.RÊGO: O cenário ao qual nos referimos nas respostas anteriores, de paulatino avanço das plataformas digitais na extração e mineração de dados de seus usuários, assim como na intervenção e direcionamento de conteúdos e potencialização da desinformação, tem levado não somente à preocupação de governos e sociedades, tendo em vista, principalmente, fatos como a eleição de Donald Trump nos Estados Unidos e a Campanha do Brexit na Inglaterra, como também tem levado a verdadeiras batalhas judiciais, além de tentativas legais de regulação da atuação das plataformas em diversos países.

Atualmente, existem modelos de regulação distintos, com predominância da autorregulação, o que mantém efetivamente o poder de decidir, por exemplo, em temas relacionados à desinformação, dentro de cada plataforma, embora estas constantemente estejam modificando sua política de transparência e tentando prestar contas à sociedade prejudicada; o que verdadeiramente acontece é que tais medidas de transparência e ética são em sua maioria unilaterais e nada transparentes, e que terminam, por exemplo, a incentivar uma cultura de cancelamento que pode ser motivada por questões justas ou de incitação ao ódio. O que o capital de predição que é considerado o novo ouro mercadológico, para além dos dados, nos aponta é para uma grande ameaça à liberdade de expressão, liberdade de pensamento ou simplesmente direito à privacidade, que aliás, como nos diz Zuboff (2020), faz muitos anos que o Facebook não mais respeita. Ao contrário, considera como um grande plus a vigilância completa dos usuários, já que tal vigilância permite não somente a mineração, mas a composição do capital de predição ao qual nos referimos anteriormente. Lembrando que o Google é ainda o maior e principal player atuante nesse mercado.

Por outro lado, eventos políticos da última década e que têm interferido nos rumos da democracia em muitos países no ocidente foram impulsionados pelo 
ecossistema desinformacional de forma intencional, o que levou a uma preocupação direta dos governos com formas de regulação das plataformas, visto que o modelo de negócios destas é interveniente no processo de potencialização da desinformação e, consequentemente, está implicado no processo de desestabilização democrática em várias partes do planeta.

Contudo, as intervenções governamentais também não podem ser pensadas ou aplicadas de modo simplista, sob pena de prejudicar ainda mais a população, empoderar ainda mais as plataformas ou instaurar sistemas de gerenciamento e controle de conteúdo com o objetivo de fiscalizar ideologicamente os usuários e censurar sua atuação.

Entre a regulação estatal e a autorregulação existe um hiato que deve ser negociado de modo amplo e transparente entre sociedade civil, governo, parlamento e plataformas. Em 2020, ocupando ainda a presidência da Federação Brasileira das Associações Científicas e Acadêmicas da Comunicação (SOCICOM), nós apoiamos a iniciativa do Observatório Latinoamericano de Observación dos Medios y Convergencia (OBSERVACOM) e do Coletivo Intervozes, que elaboraram um documento denominado Padrões para uma regulação democrática das grandes plataformas que garanta liberdade de expressão online e uma internet livre e aberta ${ }^{2}$, que propõe tanto co-regulação como regulação pública das plataformas por meio de legislação que consiga abarcar as questões intervenientes, atendendo aos anseios da sociedade e dos usuários, e em que a atuação das plataformas seja a um tempo autorregulada e direcionada por um processo legal, que preveja as determinações legais e concernentes à transparência, processos de usuários e prestação de contas à sociedade. A ideia é que a lei, a ser votada em cada país, venha a ser incluída como direcionamento para as políticas das plataformas, servindo de guia para a atuação destas e também para a fiscalização dos usuários e órgãos governamentais competentes, objetivando ainda facilitar o acesso dos usuários prejudicados

2 Disponível em https://www.observacom.org/wp-content/uploads/2020/08/Padr\%C3\%B5espara-uma-regula\%C3\%A7\%C3\%A3o-democr\%C3\%A1tica-das-grandes-plataformas.pdf. Acesso em: 22 set. 2021. 
eventualmente por uma medida unilateral de uma plataforma, ao processo que o cancelou.

A regulação das plataformas, a meu ver, não prevê somente um combate ao mercado da desinformação, mas também e, principalmente, deve prever questões que prejudicam a sociedade de forma holística, sobretudo no que concerne a questões da vigilância, extração e venda de dados, assim como, o direito à liberdade de expressão e pensamento.

\section{Referências}

BARBOSA, M; RÊGO, A. R. A construção intencional da ignorância: o mercado das informações falsas. Rio de Janeiro: Mauad, 2020.

BURKE, P. Manipulating the media: a historian's view. Revista Brasileira de História da Mídia, v. 7, n.1, p. 7-19, 2018.

ECO, U. Fascismo Eterno. Rio de Janeiro: Record, 2018.

FOER, F. O mundo que não pensa. Rio de Janeiro: LeYa, 2018.

GOMES, W. Palestra na mesa redonda: Desinformação, populismo e desinformação. Belo Horizonte: COMPOLÍTICA, 2021, 24 mai. 2021.

HABERMAS, J. Teoria do Agir Comunicativo. São Paulo: WMF Martins Fontes, 2019.

NOTÍCIAS falsas circulam 70\% mais do que as verdadeiras na rede. Veja, 10 mar. 2018. Disponível em:https://veja.abril.com.br/brasil/fake-news-circulam-70-mais-do-que-asverdadeiras-na-internet/. Acesso em: 18 jun. 2021.

POR QUE a crença de que vivemos em bolhas talvez seja um mito. BBC Brasil, 22 jul. 2018. Disponível em: https://www.bbc.com/portuguese/vert-fut-44829514. Acesso em: 20 jun. 2021

RANCIÈRE, J. O desentendimento: política e filosofia. São Paulo: Ed. 34, 2018.

RÊGO, A. R. Vigilância, controle e atenção. Revista Organicom, v. 17, n. 34, p. 82-92, 2020.

SACRAMENTO, I. Palestra na mesa redonda: Comunicação, Infodemia e combate à desinformação. São Paulo, Abrapcorp, 08 jun. 2021.

VÉLIZ, C. Privacy is power- Why and How You Should Take Back Control of Your Data. London: Transworld Publishers, 2020.

WARDLE, C.; DERAKHSHAN, H. Information disorder: Toward an interdisciplinary framework for research and policy making. Council of Europe Report DGI, 2017. Disponível 
em: https://rm.coe.int/information-disorder-toward-an-interdisciplinary-framework-forresearc/168076277c . Acesso em: 15 ago. 2020.

ZUBOFF, S. A era do capitalismo de vigilância: a luta por um futuro humano na nova fronteira do poder. Rio de Janeiro: Intrínseca, 2020. 